\title{
Effect of chronic posttrial saline injections on maze performance*
}

\author{
RENATA C. GATTONI $\dagger$ and IVÁN IZQUIERDO \\ Departamento de Farmacologia, Facultad de Ciencias Quimicas \\ Universidad Nacional de Córdoba, Estafeta 32, Córdoba, Argentina
}

\begin{abstract}
Chronic posttrial IP injections disrupt the performance of rats in a Lashley III maze for a wet food mash as a reward after 20 sessions. The treatment causes, in addition, several signs of emotional disturbance: increased latency to leave the startbox, squealing, defecation, and urination. These effects are attributable to aversive properties of the injection procedure, and these results should be considered as a cautionary note to those who study the effect of chronic posttrial drug injections on learning.
\end{abstract}

Repeated posttrial injections of amphetamine (Breda et al, 1969; Montini et al, 1970; Carlini et al, 1972), nicotine (Montini et al, 1970), or metrazol (Carlini et al, 1972) have a disruptive effect on maze performance and on training in a shuttlebox for food reward. This effect has been attributed to an aversive property of these drugs (Breda et al, 1969; Carlini et al, 1972) and is opposite to that of a single posttrial injection of any of these agents which produces, instead, an enhancement of subsequent performance through a facilitation of memory consolidation (McGaugh, 1966, 1968, Izquierdo, 1972).

The procedure of intraperitoneal injection itself, however, involves a series of manipulations which, no matter how gently they are made, may be considered as a series of aversive stimuli. Rats are grasped, lifted in the air, turned over, pricked in their abdomen, and infused with liquid through the needle. In fact, at least under certain circumstances, it appears that even saline injections may act as unconditioned aversive stimuli (Nasello \& Izquierdo, 1969; Montini et al, 1970). Thus, we decided to study the effect of a chronic treatment with posttrial intraperitoneal injections of saline on the performance of rats in a maze. For this purpose, we chose a longer period of treatment than that used in drug studies by Breda et al (1969) or by Carlini et al (1972). In a preliminary study from this laboratory, Montini et al (1970) found that chronic posttrial saline injections disrupt maze performance as much as do amphetamine or nicotine, although after a longer number of sessions.

\section{METHOD}

Twenty adult albino rats (Wistar) were used in the present study. They were weaned at the age of 30 days and received no further handling until the age of 75-90 days, at which time pretraining in a straight runway was begun (Orsingher \&

*Supported by the Consejo Nacional de Investigaciones Cientificas y Técnicas of Argentina (Grant 3917) and the Instituto Nacional de Farmacología of Argentina through a special contract.

+ Fellow of the Consejo Nacional de Investigaciones Científicas y Técnicas of Argentina.
Fulginiti, 1970). After 10 days of such pretraining, during which they received no injection whatsoever, they were trained to run a four-unit Lashley III maze for a wet food mash as a reward. Details of the apparatus and pretraining and training procedures may be found in Orsingher and Fulginiti (1970); they were essentially similar to those used by Breda et al (1969), Montini et al (1970), and Carlini et al (1972). Sessions were every $48 \mathrm{~h}$, and rats were deprived of food during the $24 \mathrm{~h}$ previous to and $1 \mathrm{~h}$ following each maze run. After each session, within $1 \mathrm{~min}$ after completion of the task ( 3 min of eating the wet mash in the goalbox), 10 of the rats received $1 \mathrm{ml} / \mathrm{kg}$ of saline $(0.9 \% \mathrm{NaCl})$; the other 10 rats received no injection or other treatment whatsoever.

\section{RESULTS}

From the 20th session on, the rats that received saline made significantly more errors (Fig. 1) and ran the maze more slowly (Fig. 2) than untreated rats. In addition, also from the 20th session on, saline-treated animals showed a higher latency to leave the startbox. This latency was $5 \mathrm{sec}$ or less after opening of the gate in all

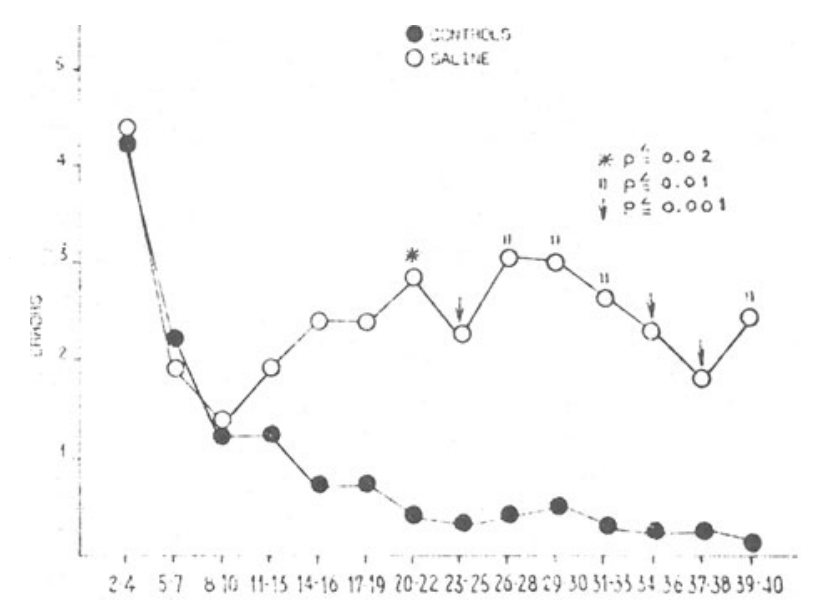

Fig. 1. Effect of chronic posttrial saline injections on the number of errors made by rats in a Lashley III maze. Ordinates-number of errors per session; abscissae-days of training (i.e., sessions) in blocks of 2-3 sessions. Each point is the mean of the number of errors per session of the whole group. Statistical evaluation, in this and in the next figure, is by way of the Mann-Whitney U-test (one-tailed). 


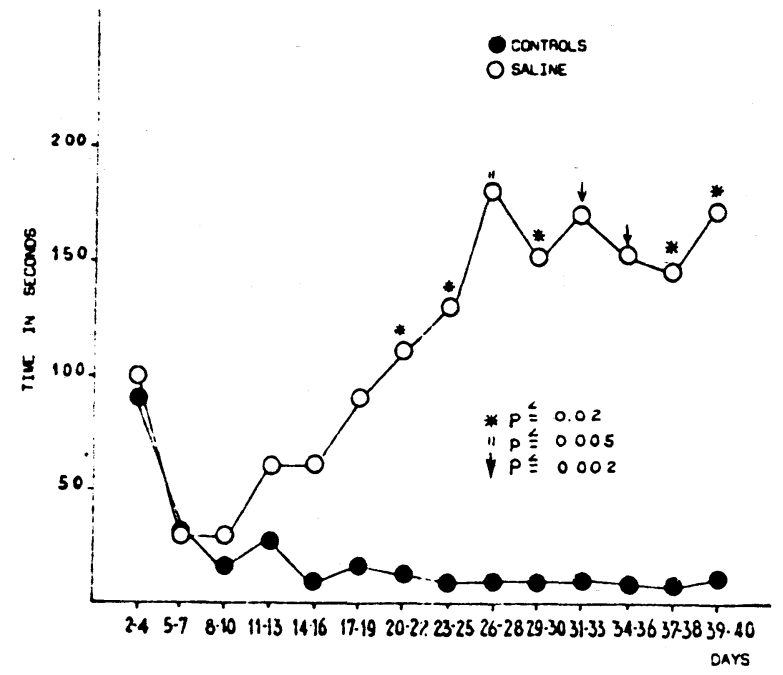

Fig. 2. Effect of chronic posttrial saline injections on running time in a Lashley III maze. Ordinates-mean running time per session in seconds; abscissae-days of training (i.e., sessions) in blocks of 2-3 sessions.

animals after 4 or 5 sessions; after the 20th session saline-treated rats always remained in the startbox more than that, occasionally as much as $10 \mathrm{~min}$ or more. In addition, in the last 10 sessions, they often squealed while refusing to leave the startbox. Furthermore, also in the last 10 or 12 sessions, all rats of the saline group defecated and urinated some time along the maze corridors; this was never observed in the untreated group. No difference in weight between both groups was detected at the end of the last session, although both were, on the average, $34 \%$ below the weight of stock rats of the same age who had not been trained in the maze.

\section{DISCUSSION}

The present results suggest that the series of manipulations involved in the intraperitoneal saline injection procedure, when repeated over many days, act as an aversive constellation of stimuli to hinder maze performance and to induce signs of emotional disturbance in rats. This effect of saline injections is remarkably similar to that reported with fewer posttrial drug injections (Breda et al, 1969; Montini et al, 1970; Carlini et al, 1972), and one is entitled to wonder whether at least part of that effect attributed to the drugs may not have been due merely to the injection procedure. In fact, the deleterious effect of drugs given by chronic posttrial injection is quite unspecific pharmacologically, since agents so diverse as amphetamine, nicotine, metrazol, or even saline have the same effect, although with a different threshold. Besides, Montini et al (1970) reported that a switch from chronic posttrial amphetamine to nicotine or to saline, or vice versa, does not reverse the disruption of maze performance initiated by any of the three. No doubt, and in spite of the cautionary tone of the present note regarding chronic posttrial injection treatments, it must be admitted that some drugs may have aversive properties of their own that may add to, or accelerate, the effect of saline. For one thing, as was said, less chornic posttrial injections are needed with amphetamine, nicotine, or metrazol to induce maze disruption than with saline (Breda et al, 1969; Montini et al, 1970; Carlini et al, 1972). For another, amphetamine, at least, but not saline, may have a punishing effect in a saccharin drinking test (Cappell \& LeBlanc, 1971).

\section{REFERENCES}

Breda, J. B., Carlini, E. A., \& Sader, N. F. A. Effects of chronic administration of $(+)$-amphetamine on maze performance in the rat. British Journal of Pharmacology, 1969, 37, 79-86.

Carlini, E. A., delorenzo, R. M. T., \& Almeida, E. T. A suggested aversive effect in rats of posttrial administration of central nervous system stimulants. Behavioral Biology, 1972, 7, 391-400.

Cappell, H., \& LeBlanc, A. E. Conditioned aversion to saccharin by single administrations of mescaline and d-amphetamine. Psychopharmacologia (Berlin), 1971, 22, 352-356.

Izquierdo, I. Hippocampal physiology: Experiments on regulation of its electrical activity, on the mechanism of seizures, and on a hypothesis of learning. Behavioral Biology, 1972, 7, 669-698.

McGaugh, J. L. Time-dependent processes in memory storage. Science, 1966, 153, 1351-1358.

McGaugh, J. L. Drug facilitation of memory and learning. In D. H. Efron (Ed.), Psychopharmacology $-A$ review of progress. PHS Publication No. 1836. Washington: U.S. Government Printing Office, 1968. Pp. 891-904.

Montini, E. E., Gattoni, R. C., \& Izquierdo, I. Efectos sobre el aprendizaje del tratamiento crónico con inyecciones post-trial de anfetamina, nicotina y salina. Proceedings of the Third Annual Meeting, Sociedad de Farmacologia Experimental de Argentina, 1970. Abstracts. Pp. 20-21.

Nasello, A. G., \& Izquierdo, I. Effect of learning and of drugs on the ribonucleic acid concentration of brain structures of the rat. Experimental Neurology, 1969, 23, 521-528.

Orsingher, O. A., \& Fulginiti, S. Effects of Cannabis sativa on learning in rats. Pharmacology, 1970, 3, 337-344.

(Received for publication December 26, 1972; revision received April 10, 1973.) 